Int.J. Hum. Soc. Dev. Res.

ISSN (P):2521-1439; ISSN (E):2523-4331

Volume 4, Number 1, 2020. 31-40

DOI:10.30546/2523-4331.2020.4.1.31

\title{
THE ANALYSIS OF SAFETY TOPICS IN MANUFACTURING INDUSTRY
}

\author{
Hayriye Sevil ERGÜR \\ Eskisehir Osmangazi University, Eskisehir, Turkey
}

(C) The Author(s) 2020

\section{ABSTRACT}

There are so many accidents and cases of health every year in all kinds of production lines at manufacturing industry. Accidents about the mechanical equipment, particularly workshop and manufacturing used in machining the metals, plastics and etc. may have consequences which range from a minor cut to the loss of a finger, hand or eye. The frequency of such accidents varies between 10 and 15 percent. Therefore, great care is required on the part of all machine operators to prevent either personal injury or injury to colleagues nearby. Every person has a duty to ensure that work is carried out in a safe manner and without foreseeable risk to the health and safety of either operators or the others. Occupational health and safety is a vital importance for businesses and the welfare and also the safety of staff. Machine-generated hazards can not be eliminated through inherently safe design, and then they must be reduced to an acceptable level, or the hazards to be isolated from the workers by allowing the minimum safety distances to be respected. All the man-machine interfaces that can affect the health and safety must be carefully established whether they are moving elements, machine components, noise, vibration, visible or invisible radiation hazardous materials or ergonomic hazard. The aim of this study is to introduce guidance on how to prevent or manage many of the health and safety planning on engineering in industries of all kinds.

\section{(C)2020.All rights reserved}

\section{ARTICLE HISTORY}

Received: 13/05/2019

Accepted: 17/12/2019

Published online: 27/04/2020

\section{KEYWORDS}

Industrial safety, health, specific risks, safety precautions, mechanical causes.

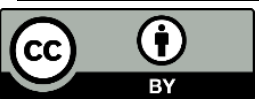

www.ijhsdr.com 


\section{Introduction}

Health and safety is one of the most important feature of human concern in manufacturing industry. An adaptation of working environment to workers for the promotion and maintenance of the highest degree are aimed. Health and safety are due to the rapid industrial development that is taking place in the developing countries. Many of these countries are moving from manual labour to mechanization in the main productive sectors, such as manufacturing, mining and agriculture. The insatiable desire of these countries for technical advancement has brought about the importation of very developed machinery and pieces of equipment not only into the industrial production sector and also assembly line. This has been associated with a change in the structure of the labour force as a whole including a rise in the employment of women (Takele \& Mengesha, 2006). The consequences of industrial safety were understood so many years ago due to millions of industrial or other accidents take place which resulted in either death or in temporary and permanent disablement of the workers. This causes loss or damage of property and wasted man-hours. So, workers must be aware of dangers existing in industry. Safety measures, rules and regulations in industry will never replace intelligent precautions taken by a worker in doing his work (Takele \& Mengesha, 2006; Starr \& Whipple, 1984).

Health and safety risks have been an expanding area of study for the last two decades, largely as a result of increasing public concern with environmental effects of industrial activities. In brief, the theoretical methods of decision-making and detailed analysis that are widely accepted for financial risks are not applied to health and safety risk decision-making (Starr \& Whipple, 1984, p.452-463). Research in health and safety is a new and rapidly developing field. Important knowledge can be extracted from the literature but it is necessary to improve the quality of the research by exchange of experience between researchers with a higher priority to interdisciplinary studies. Most countries have basic requirements that employers must meet as regards the organization of health and safety. Some enterprises generally have difficulties in fulfilling these requirements (Frick, Jensen \& Quinlan et al., 2000).

\section{Planning for industrial safety}

A large number of industrial accidents can be reduced to the minimum ones through careful safety planning within an industrial production line. All these 
unwanted events can be prevented by effective planning for safety. Safety consideration includes proper layout of workshops and equipment, such as providing sufficient ventilation, adequate working area to the operator and clear pathways for movement of materials and parts, provision for personnel facilities (Stranks, 2006). Careful planning in advance for optimized and safe layout of design and manufacturing activities for ensuring the safety of industry in the manufacturing and inventory areas. Several codes and standards for industrial safety, health and hygiene, fire prevention, etc. have been prescribed by governments and other safety agencies and they should be fully taken care of at the planning and implementation stages of a production line. A number of important features should be considered and suitably incorporated planning the layout of a new plants for safety (Hasle \& Limborg, 2006).

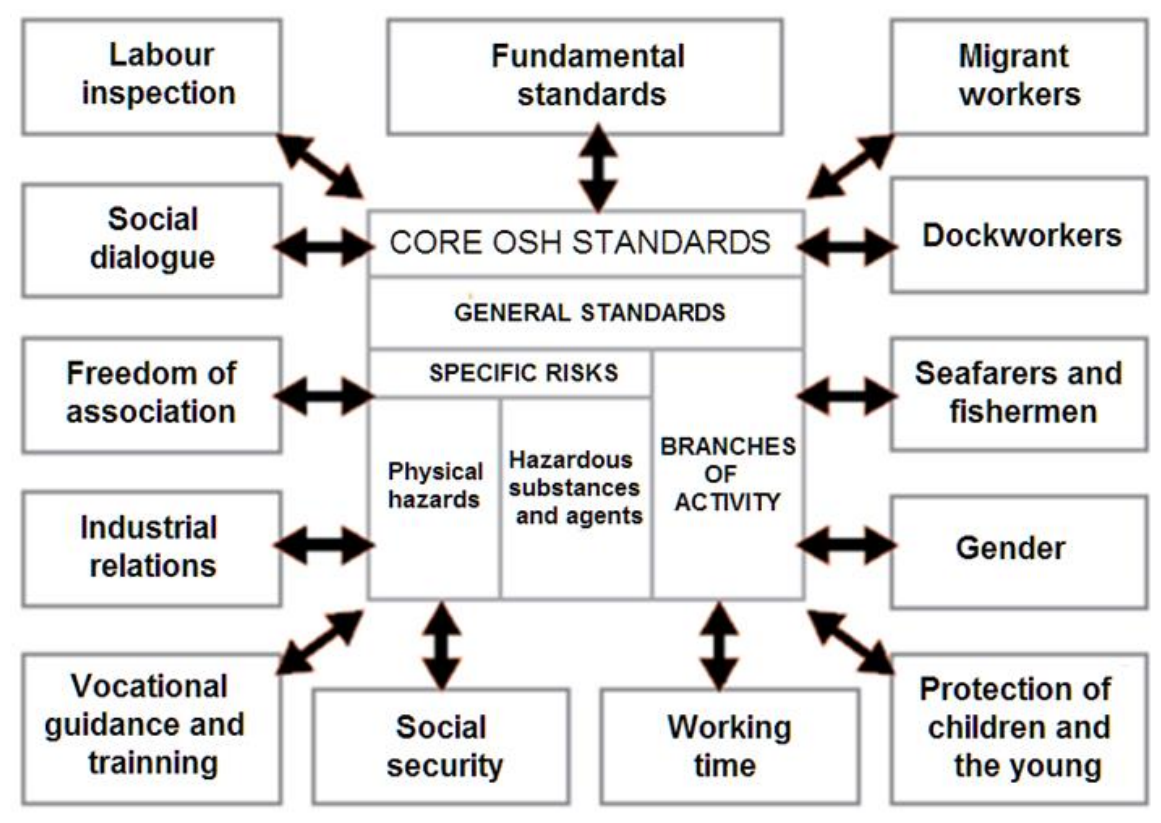

Figure 1 Relations of OSH standards to ILO standards on other issues (Kang et al., 2017)

International labour standards covering general conditions of employment, social security, and the employment of women, children and other categories of workers also have a bearing on safety, health and the working environment. Moreover, a series of conventions and recommendations specifically covers the health and safety. Figure 1 shows how the ILO's core OSH standards relate to these other issues (Kang, Park, Eom, Choi, Lee \& Myong, 2017). The aim of industrial safety is to avoid all kinds of casualty in the plant by decreasing the endanger to minimum value in order to eliminate accident caused blockage and lost production by 
lowering workmen's compensation and limit all other direct and indirect costs of accidents. The objectives of industrial safety can be outlined as:

- Industrial safety is needed to check all the possible chances of accidents for preventing loss of life and permanent disability of any industrial employee.

- It is needed to prevent accidents in industry by reducing any hazard to minimum.

- It is needed to reduce workman's compensation and all the cost of accidents.

- It is required to educate safety principles to avoid accidents in industry.

- It is required to have better human relations within the industry.

\section{Accidents and Causes}

The accidents are the mishaps leading injury to workers, machines or tools and equipment may cause injury and result either death or temporary and permanent disablement of the industrial employees. An industrial accident may be defined as an event, detrimental to the health of worker, suddenly occurring and originating from external sources, and which is associated with the performance of a paid job, accompanied by an injury, followed by disability or even death. Few industries determine the accidents by the extent to which it leads to the disablement of the victim and number of hours or days in order to remain absent from duty on account of the problem (Hasle \& Limborg, 2006, p.6-12).

The direct costs involve payment of compensation and overheads uncompensated wage losses of the injured employees, cost of medical care and hospitalization. Proper diagnosis of causes of mishandling and corrective measures of the same always help in preventing future accidents. Every care and prevention therefore should be evolved adopted to prevent accidents to the maximum possible extents. If someone is honest with himself, he cannot think of a single accident that could not have been prevented by care (Fabiano, Curro \& Pastorino, 2004, p.587$600)$. 


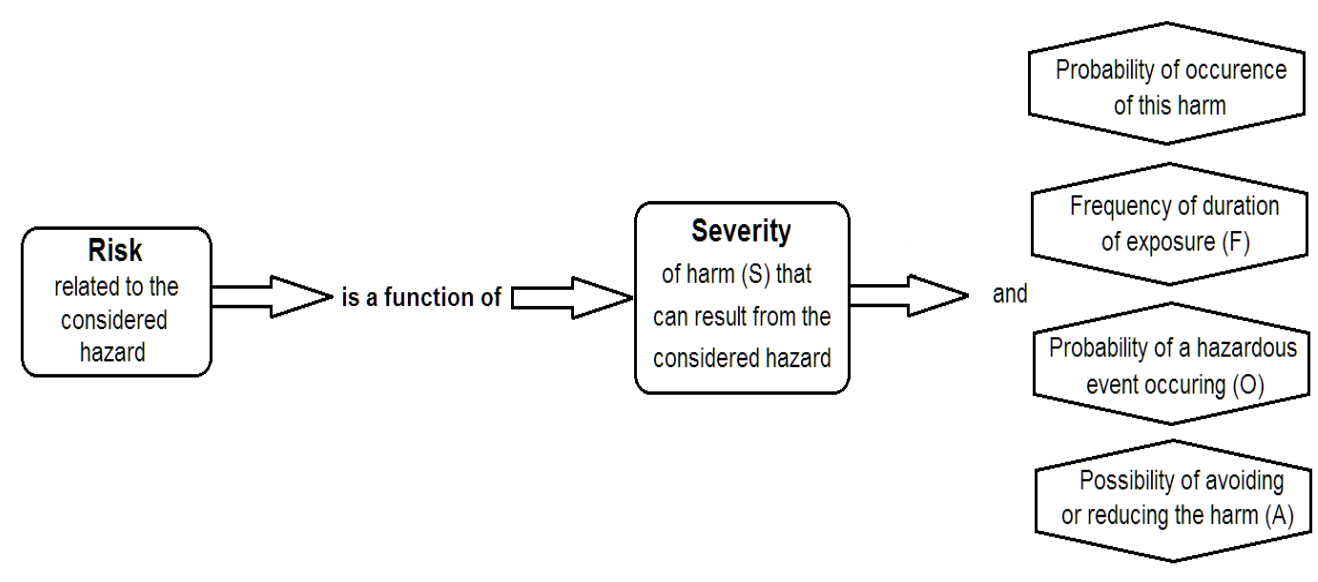

Figure 2. Elements of risk (Wilks \& Page, 2003)

Risk is defined as in Figure 2 with the combination of the severity of the harm (S) and the probability of occurrence of this harm. The probability of the harm occurring can be divided into three parts such as the frequency and duration of exposure to the hazard $(\mathrm{F})$, the probability of a hazardous event occurring $(\mathrm{O})$ and the possibility of avoiding or reducing the harm (A).

\subsection{Human Causes}

The frequency of occurances on human causes can be outlined with the help of major factors.Accidents may take place while working on unsafe, dangerous equipments or machineries possessing rotating, reciprocating and moving parts occur while operating machines without knowledge, safety precautions, authority, and safety devices. They generally happen while operating or working at unsafe speed and for long duration of work, shift duty etc. Use of improper tools, working with mental worries, ignorance, carelessness, nervousness, dreaming will also be the reason of accidents. The main reasons for unexpected accidents may be standing apart from the personal protective devices (Wilks \& Page, 2003).

\subsection{Environmental Causes}

Accidents may occur during working at improper temperature and humidity which causes fatigue to the workers so chances of accidents increases with workers having fatigue. The presence of dust fumes and smoke in the working area and also poor workshop congestion, blocked exits, bad plant layout may cause accidents. On the other hand, accidents occur due to inadequate illumination and also improper ventilation in the plant (Mills, 2012, p.1-7). 


\subsection{Mechanical Causes}

Accidents caused by mechanical factors that are entirely chargeable to unit or equipment breakdown. Normally, mechanical factors are inhibitable for causes. They are totally less than $10 \%$ of the number of industrial accidents. The use of poor maintained or unsafe equipment may terminate accidents and they may come about unguarded and improper guarded equipment. Insecure processes, design and construction of any structure may escort to accidents in the factory. They may also happen due to conveying system and faulty layout (Alli, 2008).

\subsection{Common Sources of Accidents}

A large number of revolving, rotating, reciprocating and moving parts of machinery can be said as the sources of danger and require guarding for protection against accidents. Extensive studies reveal that some characteristic groups of dangerous parts are acting as common sources of accidents in workshops (Alli, 2008). Many major sources are outlined as rotating parts, shielding all kinds of fasteners of rotary parts, random feed mechanisms, shafts and spindles, rotary worms and spirals, reciprocating tools and dies of presses, spring hammer, drop hammers, and presses, rotary drums and cylinders without casing, such as all kinds of mixers, rotating weights, nips between meshing racks and pinions of machine parts, nips between crank handles for machine controls and fixed parts (Kang, Park, Eom, Choi, Lee \& Myong, 2017).

\section{Preventive measures}

Few safety measures commonly used in industries comprise of the proper safety guards for reciprocating machine components such as hammers, presses, shaper, slotter, power hacksaw, paper cutters, fencing of dangerous and rotating parts like revolving shafts, incorporating safety devices such as safety valves, rigid construction of heavy items like hoists, cranes, proper insulation of electric wire and earthing of electric appliances, wearing appropriate safety shoe and other necessary items for body protection, maintenance cleanliness of shop floor, removal of metal chips with proper protection, avoiding fire hazard. Safety is the safety of human being and the safety of workshop machinery. Hence there is a great need for 
the study of the domain of industrial safety for accidents prevention and good workshop keeping is the utmost.

Safe working conditions in industries may help to minimize the number of accidents taking place, prevent premature death of talented employee and needless pain and suffering to industrial employees, reduce damages to equipment and machinery, increase production and reduce the cost (Park et al. 2013). Careless handling of heavy materials and components is a major source of back and foot injuries. Full use should be made in order to avoid premature fatigue of transport workers mechanized materials handling equipment by using mechanical means of conveyance to ensure the safety of workers engaged in material handling. Personal protective devices such as safe hard hats, rubberized hats for protection against liquids, chemicals, ear protectors, face mask and face shields are used for prevention (Jenny, 2001, p.151-172; "Healt and Safety" in management system, 2015).

\section{Common Safety Methods}

The common methods of safety are by construction or accurate design and by position with fixed guards, interlock guards, automatic guards, trip guards and distance guards. Workplace layout, proper operating conditions and proper material conveying with personal protective devices are also usual techniques. Turning, pressing, grinding, sawing, bending, boring, combination metalworking machines, manual handling and welding are production examples which can have guidance for preventing and dealing with the risks (Singh, 2006).

\subsection{Pressing}

By pressing the either foot pedal or hand switch on presses, the guard will be fully closed slowly while the extractor remains locked. After unlocking the extractor, the pedal pressure will actuate the extractor into the clutch engaged position where the guard control switch be clear in controlling the disc cup with the pedal kept depressed check in order to ensure the close position (Singh, 2006).

\subsection{Sawing}

The main hazards for operators of this type of machine originate from adjoin with the unsafe rotating toothed saw blade. The rotating blade presents a risk and can draw a person into the machine during feeding, adjusting or retrieval of 
workpieces. Operators may be also be exposed to additional risk of injury during swarf removal or cleaning, particularly where the machine is left running while such tasks are being undertaken. Many of the accidents that result in very serious injury to the operator's hands and arms including amputations. The majority of sawing accidents are associated with inadequate standards of guarding where a view is required, transparent or mesh materials may be used in fixed guards. All pertinent health and safety information and instructions on the safe use of pivotinghead metal-cutting circular saws must be made nearby operators (Singh, 2006).

\subsection{Bending}

The most important risk at these machines is the operator's hands being caught and drawn into the in-running nip which is created by rotating rollers. Injury is most likely to occur during the initial feeding of the work piece into the rolls. There may be additional risks, such as trapping of hands between the moving workpiece and other fixed parts of the machine. A high proportion of the accidents are associated with the operator wearing gloves. The likelihood of entanglement in the in-running nip created between the counter rotating rollers is increased if gloves are worn (Travis, Bennett, Haines, Pang, Bhutta, Hyder, Pielemeier, Mills \& Evans, 2004, p.900-906).

\subsection{Boring}

The hazards associated with boring machines include entanglement at the rotating chuck and cutting tools. Crushing or trapping may also arise from the other moving parts. The automated nature of $\mathrm{CNC}$ machines means that additional risks to safety may be present as machine movement is not always secure or liable. Injuries may occur during machining observation, setting and adjustment or swarf removal. Accident history shows that serious injuries, including severe lacerations, crushing or amputation, occur on these machines (Travis et al. 2004, p.900-906; Gilson, 2012)

Other injuries include skull fracture and broken limbs. For health and safety executive in risk assessment, one will need to consider all operations where access to the work zone is required. This will include routine machining operations, observation and adjustments and maintenance tasks (Gilson, 2012). 


\subsection{Metalworking Machines}

Mechanical risks, including trapping, crushing and exposure to cutting tools, exist at the different work stations on combination metalworking machines. Trapping or crushing hazards may also arise from unintended or uncontrolled movement of the workpiece and although uncommon injuries from the ejection of broken tooling have occurred. A significant number of injuries are associated with tasks that involve small workpieces (Gilson \& Raphaely, 2008; Hämäläinen, Takala \& Saarela, 2006). It is important that the limitations of these machines are recognized by both employers and operators. The manufacturer's recommendations must be followed in relation to limits for metalworking machines.

\section{Conclusion}

Researches in health and safety is a new and rapidly developing field. An important knowledge can be extracted from the literature but it is necessary to improve the quality of the study with emphasis on the use of exiting knowledge in new research. Occupational health and safety system is necessary to ensure the long-term deployment and productivity of the workforce. Health and safety system should prevent an injury or illness and are forced to call in sick due to their work or working conditions. The investment in industrial accidents was greater when health and safety issues were recognized as important. In particular, the study analyzed the safety and health issue awareness and facility investment experiences as well as the industrial accident occurrence in the past to estimate the causal relationships between them. Health and safety creates the physical work environment which embraces the promotion and maintenance of physical, mental and social well-being of employees or workers in the organization. It includes reducing work related injury, illness and disability by addressing the harmful hazards and risks of the physical environment. Planning is essential for the implementation of safety and health policies. Adequate control of risks can be achieved only through coordinated action by all members of the organization. An effective planning system requires a safety and health management system that controls risks and as a minimum complies with related laws, reacts to changing circumstances and demands, promotes and sustains a positive safety and health culture and supports continual improvement in safety and health performance.

\section{Disclosure statement}

No potential conflict of interest was reported by the author.

Contact Information.

Email address: hsergur@ogu.edu.tr 


\section{References and notes:}

Alli O.B. (2008). Fundamental principles of occupational health and safety, $2^{\text {nd }}$ ed. Geneva: International Labour Office.

Fabiano, B., Curro, F., \& Pastorino, R. (2004). A study of the relationship between occupational injuries and firm size and type in the Italian industry. Safety Science, 42(1), 587-600.

Frick, K., Jensen, P.L., \& Quinlan, M. et al. (2000). Systematic occupational health and safety management-perspective on an international development. Amsterdam: Pergamon Press.

Gilson, L. (2012). Health policy and systems research: A methodology reader. Switzerland: World Health Organization (WHO) Library.

Gilson, L., \& Raphaely, N. (2008). The terrain of health policy analysis in low and middle income countries: a review of published literature 1994-2007. Health Policy and Planning, 23(5), 294-307.

Hämäläinen, P.; Takala, J., \& Saarela, K.L. (2006). Global estimates of occupational accidents. Safety Science. 44(1), 137-156.

Hasle, P., \& Limborg, H.J., (2006). A review of the literature on preventive occupational health and safety activities in small enterprises. Industrial Health, 44(1), 6-12.

Health and Safety Service (2015). Health and safety management system. Retrieved from bronbury.com/wp-content/uploads/2015/02/Bronbury-Health-and-SafetyManagement-System.pdf

Jenny, B. (2001). Accurate assessment of OHSMS performance: Impact of auditor skills. In Warwick Pearse, Clare Gallagher and Liz Bluff (Ed.) Occupational health \& safety management systems. 151-172. Australia: Cleveland Printing.

Kang, Y.J., Park, J.H., Eom, H., Choi, B., Lee, S., Lee, J.W., \& Myong, J.P. (2017). Participation inequality in the National General Health Examination based on enterprise size. Annals of Occupational and Environmental Medicine, 29(3), 1-9.

Mahmood.A.,Sarfraz.M., Atib Ramzan.M and Ibrahim Abdullah.M.(2018). Impact of creativity on Entrepreneurial intentions through self-efficacy.International Journal of Humanities and Social Development Research. DOI:10.30546/2523-4331.2018.2.1.52. Azerbaijan, Baku. Volume 2, Number 1..52-73

Mills A. (2012). Health policy and systems research: defining the terrain; identifying the methods. Health Policy and Planning 27(1), 1-7.

Park, J., Jeong, H., Hong, S., Park, J.T., Kim, D.S., Kim, J., \& Kim, H.J. (2013) Effects of health and safety problem recognition on small business facility investment. Annals of Occupational and Environmental Medicine, 25(26), 1-10.

Singh, R. (2006). Introduction to basic manufacturing processes and workshop technology. New Delhi: New Age International Ltd.

Starr, C., \& Whipple, C. (1984). A Perspective on Health and Safety Risk Analysis. Management Science, 30 (4), 452-463.

Stranks, J. (2006). Health \& Safety Handbook: A practical guide to health and safety law, management policies and procedures. Great Britain: Kogan.

Takele, T., \& Mengesha, A. (2006). Occupational Health and Safety. The Carter Center, The Ethiopia Ministry of Health: University of Gondar, The Ethiopia Ministry of Education.

Travis, P., Bennett, S., Haines, A., Pang, T., Bhutta, Z., Hyder, A.A., Pielemeier, N.R., Mills, A., \& Evans, T. (2004). Overcoming health-systems constraints to achieve the millennium development goals. Public Health, 364(4), 900-906.

Wilks, J., \& Page, S.J. (2003). Managing Tourist Health and Safety in the New Millennium (Advances in Tourism Research), 1st ed. Boston: Pergamon Press. 